\title{
Survey results from The Anesthesia Clerkship Pocket Guide for Medical Students-promoting free open medical education resources in anesthesia
}

\author{
Grace M. Xu, BHSc (1) - Kevin Latchford, MD, PhD • Daniel Cordovani, MD, \\ MSc
}

Received: 16 November 2020/Revised: 13 January 2021/Accepted: 14 January 2021/Published online: 2 February 2021

(C) Canadian Anesthesiologists' Society 2021

\section{To the Editor,}

Anesthesia is a mandatory two-week clerkship rotation in most Canadian medical schools. Yet student exposure and anesthesia-specific teaching remains low in undergraduate medical education, a sentiment that has been persistently noted. ${ }^{1-4}$ This may be due to a variety of factors including limited pre-clinical familiarity and knowledge, and inconsistent highlighting of crossdisciplinary knowledge between anesthesia and other specialties. ${ }^{3}$ There are currently several specialty-specific, quick-reference handbooks used by McMaster University medical students that address core objectives and supplement their experiential learning. McMaster University has previously published Understanding Anesthesia: A Learner's Handbook by Dr. Karen Raymer (https://anesthesiology.queensu.ca/source/

UnderstandingAnesthesia1_1_2.pdf)—a free, innovative, and widely used iBook for medical students.

Electronic supplementary material The online version of this article (https://doi.org/10.1007/s12630-021-01929-z) contains supplementary material, which is available to authorized users.

G. M. Xu, BHSc (ه) .

Michael G DeGroote School of Medicine, McMaster University, Hamilton, ON, Canada

e-mail: grace.xu@medportal.ca

K. Latchford, MD, PhD

Department of Anesthesia, Grand River Hospital and St. Mary's General Hospital, Michael G. DeGroote School of Medicine, McMaster University, Hamilton, ON, Canada

D. Cordovani, MD, MSc

Department of Anesthesia, Hamilton Health Sciences, Michael

G. DeGroote School of Medicine, McMaster University,

Hamilton, ON, Canada
Nevertheless, it is written as an introductory textbook and is not well-suited as a bedside handbook.

Seeing this gap in Canadian-based handbooks specific to anesthesiology, and to engage more students and optimize learning during their limited core anesthesia exposure, we conceptualized the Anesthesia: A Clerkship Pocket Guide (https://mcmasteracp.ca) in December 2018. Our goal was to provide a free supplementary anesthesia-specific educational resource that would accommodate different learners' preferences and is specifically targeted to clinical clerks. ${ }^{5}$ Compared with traditional textbooks, lectures, or online modules, it is optimized for accessibility which increases asynchronous learning opportunities throughout the clinical day and promotes a flipped model of teaching in the operating room. ${ }^{5} \mathrm{We}$ designed the resource based on McMaster's undergraduate medical education anesthesia learning objectives. It includes both anesthesia-specific and cross-disciplinary extensions of knowledge to engage students with varied interests. The content was reviewed by a team of clerks, anesthesia residents, and staff anesthesiologists before being disseminated across Canada through social media and outreach to the Clerkship Directors subcommittee of the Association of Canadian University Departments of Anesthesia. A confidential user survey (eAppendix in the Electronic Supplementary Material) is automatically generated and has to be completed to access the book; the website cookies allow an individual repetitive access without needing to resubmit the survey. Institutional ethics approval was waived because the survey was used for quality improvement.

From 13 April 2020, when it was first published online, to 31 December 2020, the survey has been completed by 656 respondents from across 16 medical schools in Canada and abroad. Most survey respondents were from three 


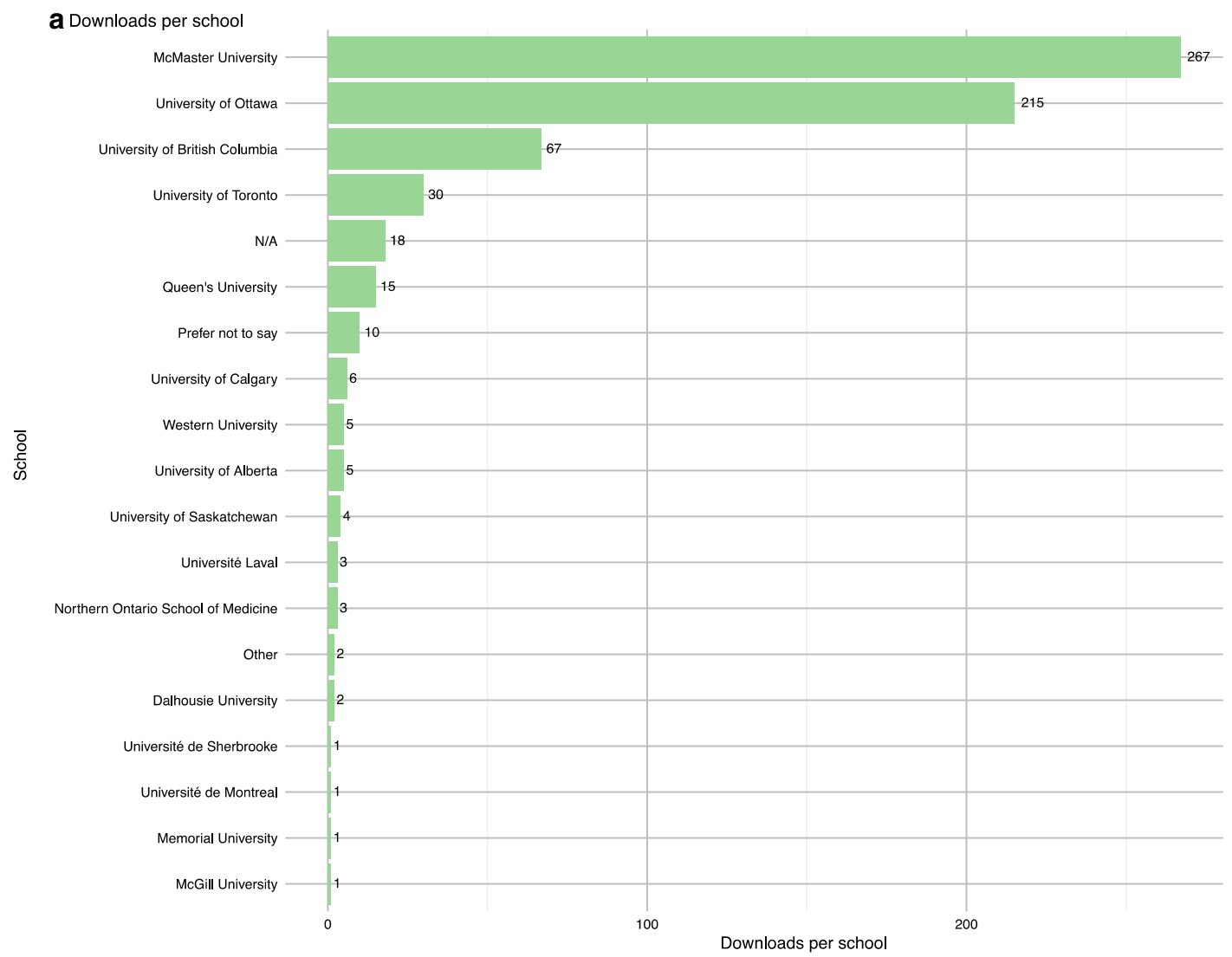

bPreparedness for anesthesia core

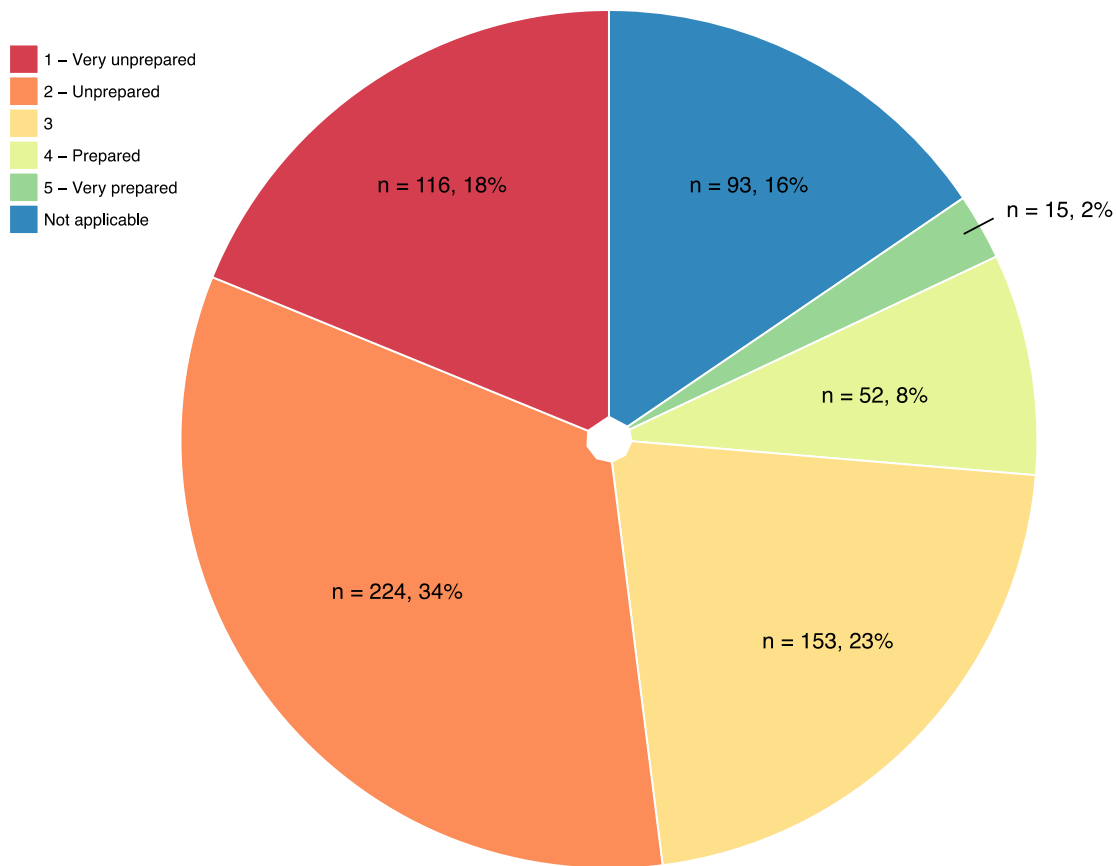

Figure Selected Anesthesia Clerkship Pocket Guide user survey dataa) Downloads per school; b) preparedness for anesthesia core 
programs that have incorporated the book into their anesthesia clerkship materials-McMaster University ( $n=267 ; 41 \%)$, the University of Ottawa $(n=215$; $33 \%$ ), and the University of British Columbia ( $n=67$; $10 \%$ ) (Figure a). Most students indicated their intent to use this resource for their core rotation $(n=460)$ and self-study ( $n=394)$, with some using it during a clinical elective $(n=$ 114). Most students $(n=339 ; 52 \%)$ were not interested in pursuing anesthesia while $27 \%(n=178)$ remained undecided.

Notably, most students $(n=340 ; 52 \%)$ felt either "unprepared" or "very unprepared" for their anesthesia rotation, while only $10 \%(n=67)$ felt "prepared" or "very prepared" (Figure b). These survey results correspond with previous research highlighting the lack of significant preclerkship exposure and teaching despite anesthesia being a mandatory rotation in the curriculum of most Canadian medical schools. ${ }^{2-4}$

Based on our experience as medical students entering and having undertaken anesthesia rotations, and on the insights gained from this survey, we suggest the following for increasing the readiness of students to optimize their learning from anesthesia:

- Encourage the creation and sharing of free anesthesia resources that decrease monetary barriers and increase accessibility for students on a variety of learning platforms;

- Focus on eliciting specific topics that cause students to feel unprepared entering their anesthesia rotation and create objectives that address them in a pre-clinical foundation;

- Highlight some of the key overlaps in anesthesiology with other sub-specialty areas in both pre-clerkship and clerkship rotations (e.g., management of obstetrical emergencies; management of acute and chronic pain).
Acknowledgements I would like to sincerely thank the Michael G. DeGroote School of Medicine Waterloo Regional Campus Research for their support and funding, with special thanks to Graham Campbell, Sarah Penhearow, Connor MacAlpine, and Bjorn Rave for their dedicated work for this project. Also, I acknowledge and sincerely appreciate the contributions of all the reviewers and staff who have worked on and shared this resource for their students.

Disclosures None.

Funding statement Funding of the print materials and website was provided by the Waterloo Regional Campus of the Michael G. DeGroote School of Medicine, McMaster University.

Editorial responsibility This submission was handled by Dr. Hilary P. Grocott, former Editor-in-Chief, Canadian Journal of Anesthesia.

\section{References}

1. Griffith HR. Medical education and anesthesiology. Can Med Assoc J 1964; 90: 852-3.

2. Brull R, Bradley $J W$. The role of anesthesiologists in Canadian undergraduate medical education. Can J Anesth 2001; 48: 147-52.

3. Adudu OP, Le NH, Devito I, Campbell FA, Levine MF. Medical student impressions of anesthesiology and anesthesiologists. Can J Anesth 2010; 57: 792-3.

4. Hamlin $C$, Bhangu $K$, Villafranca A, et al. Participation of Canadian anesthesiology departments in undergraduate medical education. Can J Anesth 2017. https://doi.org/10.1007/s12630016-0761-4.

5. Kurup V, Hersey D. The changing landscape of anesthesia education: is Flipped Classroom the answer? Curr Opin Anaesthesiol 2013; 26: 726-31.

Publisher's Note Springer Nature remains neutral with regard to jurisdictional claims in published maps and institutional affiliations. 